OPEN ACCESS

Edited by:

Justyna Godos,

University of Catania, Italy

Reviewed by:

Agnieszka Micek,

Jagiellonian University, Poland

Roberta Masella,

National Institute of Health (ISS), Italy

*Correspondence:

Dawid Made

dawid_madej@sggw.edu.pl

Specialty section:

This article was submitted to

Nutritional Epidemiology,

a section of the journal

Frontiers in Nutrition

Received: 05 August 2021 Accepted: 15 September 2021

Published: 15 October 2021

Citation:

Madej D, Granda D, Sicinska E and Kaluza J (2021) Influence of Fruit and

Vegetable Consumption on

Antioxidant Status and Semen Quality:

A Cross-Sectional Study in Adult Men.

Front. Nutr. 8:753843.

doi: 10.3389/fnut.2021.753843

\section{Influence of Fruit and Vegetable Consumption on Antioxidant Status and Semen Quality: A Cross-Sectional Study in Adult Men}

\author{
Dawid Madej*, Dominika Granda, Ewa Sicinska and Joanna Kaluza
}

Department of Human Nutrition, Institute of Human Nutrition Sciences, Warsaw University of Life Sciences-SGGW, Warsaw, Poland

The influence of fruit and vegetable consumption on semen quality by reducing oxidative stress is inconsistent. Thus, the association between the consumption of these products, antioxidant status, and semen quality was investigated in 90 men aged 18-40. The consumption of fruit and vegetables was collected using the 3-day food record method. Antioxidant status: total antioxidant capacity in semen (TAC-s) and blood (TAC-b), blood superoxide dismutase (SOD-b), glutathione reductase (GR-b), glutathione peroxidase (GPX-b), catalase (CAT-b) activity, and malondialdehyde concentration in blood (MDAb) were measured. Sperm concentration, leukocytes in the ejaculate, vitality, motility, and sperm morphology were examined using computer-aided semen analysis (CASA). The consumption of fruit and vegetables was positively correlated with sperm concentration, vitality, motility, TAC-s, TAC-b, and SOD-b activity. The TAC-s and TAC-b were positively related to motility, TAC-s was inversely correlated with sperm tail defects. The SOD-b activity was positively correlated with vitality, motility, sperm morphology, and inversely with sperm tail defects and leukocytes in the ejaculate. Compared to the men in the first quartile of fruit and vegetable consumption ( $<318 \mathrm{~g} /$ day), those in the highest quartile (>734 g/day) had the highest sperm concentration, vitality, motility, TAC-s, TAC-b, GPx-b activity, and the lowest MDA-b concentration (based on multivariate regression models). A high consumption of fruit and vegetables may positively influence selected sperm quality parameters by improving the antioxidant status of semen and blood.

Keywords: antioxidant defenses, blood, semen, infertility, fruits, vegetables

\section{INTRODUCTION}

Results of epidemiological studies confirm the growing problem of idiopathic infertility in men. It is estimated that the problem of male infertility may affect up to $50 \%$ of couples in the world; however, this value may be underestimated because it does not reflect all world regions (1). Many factors contribute to its development, i.a. environmental pollution, lifestyle, chronic diseases, and oxidative stress (2-4).

Reactive oxygen species (ROS) play a physiological role in spermatogenesis, i.a. they regulate the sperm maturation process and ability to fertilize (5-7). However, their excess can cause oxidative stress. Long-term oxidative stress leads to reproductive cell damage, including increased sperm cell membrane lipid peroxidation, decreased motility, and damaged sperm DNA. 
Moreover, it may increase the number of leukocytes in semen and lead to hormone fluctuations (e.g., testosterone), causing disorders in the functioning of the male reproductive system and significantly reducing the ability to fertilize $(3,8-10)$. Thus, assessing the level of oxidative stress in the body should be included in male infertility diagnosis, and may be a useful tool in determining the ability to fertilize sperm (11).

The defense system, against ROS in male reproductive cells includes antioxidant enzymes and non-enzymatic substances like vitamin $\mathrm{C}, \mathrm{A}, \beta$-carotene, folate, and polyphenols, present among others in fruit and vegetables $(6,12,13)$. Many studies confirm the beneficial effect of specific antioxidant nutrients on improving the male reproductive system's antioxidant status, sperm quality, and support in treating idiopathic infertility (1419). Also, the dietary fiber present in fruit and vegetables may reduce oxidative stress by participating in the assimilation of polyphenols and carotenoids in the intestine and modulating the immune system's response by having a positive impact on the gut microbiome $(20,21)$. Some studies indicated that the consumption of fruit and vegetables, as well as pro-healthy eating patterns (frequent consumption of i.a. fruit, vegetables, whole-grain products, legumes, and nuts), may be connected with better semen quality (22-27). In contrast, in other studies, a beneficial influence of pro-healthy dietary patterns on the quality of semen was not observed $(28,29)$, and results on associations between dietary fiber intake and hormone levels affecting the male reproductive system were inconsistent (3034). These inconsistent results may be down to the effect of the presence of pesticide residues, heavy metals and nitrate in fruit and vegetables, substances that can cause the generation of ROS, and have a proven negative impact on sperm quality $(3,35-37)$.

Considering that the influence of fruit and vegetable consumption on semen quality is inconsistent and no study has analyzed their consumption in relation to antioxidant status and semen quality simultaneously, this study aimed to examine the association between fruit and vegetable consumption, antioxidant status, and semen quality in adult men.

\section{MATERIALS AND METHODS}

\section{Participants and Study Design}

The cross-sectional study was conducted on 90 men, aged 1840 years old, from 2018 to 2019. Men were recruited based on voluntary applications. Information encouraging participation was disseminated on social media, in gyms, and in sports clubs located in Warsaw. Inclusion criteria were: male gender and age (18-40). The criteria of exclusion were: diagnosed infertility or sterility, permanent injuries, acute or chronic reproductive system diseases, surgery of reproductive organs within the past year, diagnosed hormonal disorders or hormone therapy within the last year, chemotherapy, radiotherapy, a disease requiring special dietary treatment, or limitation of legal capacity. All participants gave written informed consent to participate in the study prior to inclusion. The study was approved by the Ethical Committee at the Institute of Human Nutrition Sciences, Warsaw University of Life Sciences (N08/2016) and was performed in accordance with ethical standards laid down in the 1964 Declaration of Helsinki and its later amendments.

A self-administered questionnaire was used to collect information on sociodemographic and lifestyle factors like sleeping time, smoking cigarettes, alcohol consumption, and using supplements. Weight and height were measured with a calibrated scale and stadiometer with an accuracy of $0.1 \mathrm{~kg}$ and $0.1 \mathrm{~cm}$, respectively. The data was used to calculate the Body Mass Index (BMI) as weight $/$ height ${ }^{2}\left(\mathrm{~kg} / \mathrm{m}^{2}\right)$. Physical activity (MET-h/week) was assessed base on the long version of the validated International Physical Activity Questionnaire (IPAQ), which considers the average time and frequency of individual activities related to everyday life and sports (38).

\section{Fruit and Vegetable Consumption}

Fruit and vegetable consumption as well as energy intake were assessed using the 3-day food record method covering two weekdays and one weekend day. During the same week as the diet data, blood collection, and sperm donation were conducted. Before filling in the food records, the participants were trained how to record detailed information about the foods and drinks consumed, preparation meals methods and recipes, and how to determine the estimate portion size by using kitchen scales and household measures (i.e., spoons, cups, bowls), and were given an album of photographs of food products and dishes. A qualified interviewer accurately checked the returned questionnaires, and possible missing or imprecise information about the food consumed and portion sizes were completed. The obtained data were entered into the "Dieta 6" software developed by the National Institute of Public Health-National Institute of Hygiene in Poland (NIPH-NIH). The software contains current food composition tables also developed by NIPH-NIH.

\section{Collection and Blood Analysis}

The fasting blood samples were collected in the morning by a registered nurse at a clinic. Anticoagulant (heparin or EDTA) tubes were used to obtain whole blood samples. The tubes without anticoagulant were centrifuged at 2,000 $\times \mathrm{g}$ for $15 \mathrm{~min}$ and at $4^{\circ} \mathrm{C}$ to obtain the serum. All blood samples were partitioned and stored at $-80^{\circ} \mathrm{C}$ for further analysis. The hemoglobin level in whole blood, as well as the concentration of total testosterone, prolactin, the follicle-stimulating hormone (FSH), and high-sensitivity C-reactive protein (hs-CRP) in serum, were determined by a certified laboratory. The assay kits (Roche, Switzerland) and Cobas 8000 analyser (Roche, Switzerland) were used to measure the hormone level using the electrochemiluminescence method, and the hs-CRP by applying the immunoturbidimetric method.

\section{Semen Analysis}

The semen samples were obtained by masturbation into a sterile container in a certified laboratory's private room 2-7 days after last ejaculation. Analyses were performed according to the World Health Organization (WHO) laboratory manual for the examination and processing of human semen by an experienced technician (39). The sperm concentration, amount of leukocytes in the ejaculate, vitality, total and progressive 


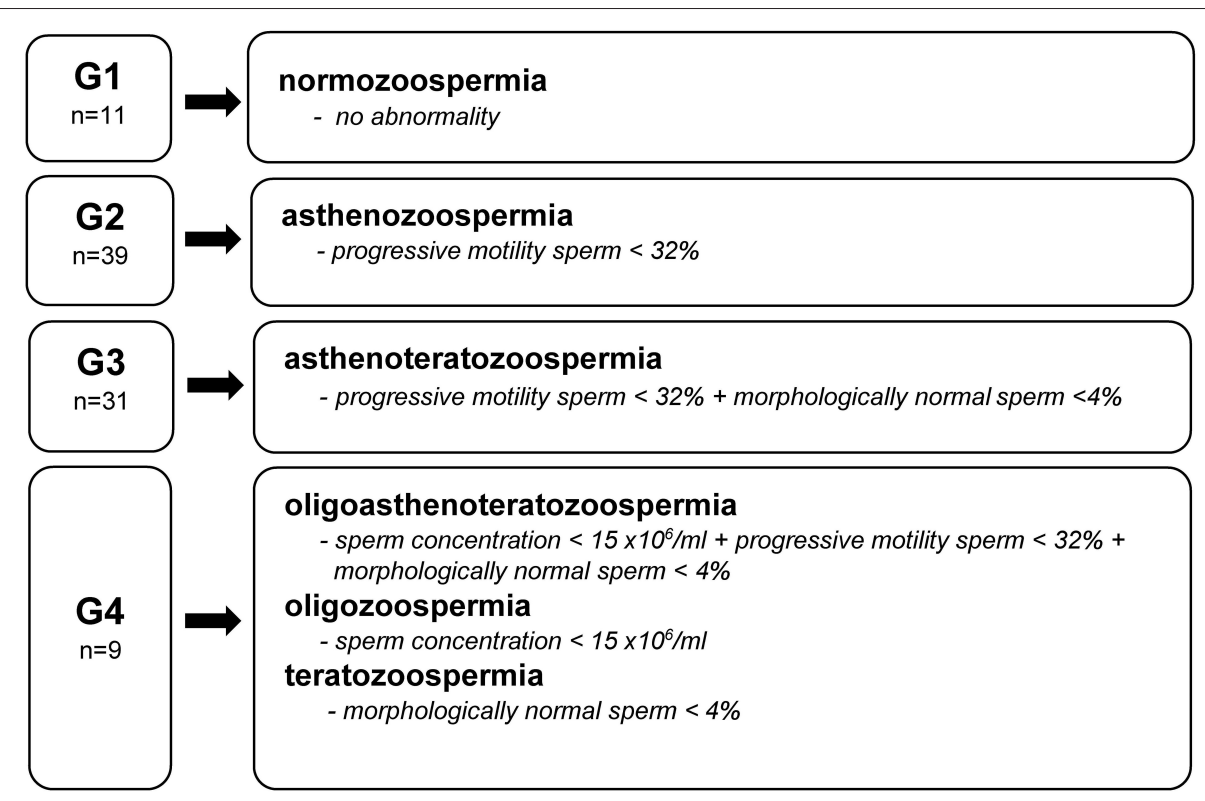

FIGURE 1 | Groups (G) of men by semen diagnosis and WHO reference value (39).

motility, sperm morphology, and sperm head and tail defects were examined using computer-aided semen analysis (CASA) (SCA Scope, Microptic, Spain). The obtained results were compared to the reference values presented by the WHO (39). Based on the diagnosis of an embryologist and WHO semen quality nomenclature (39), the studied men were divided into four groups (Figure 1). Group 1 (G1) included men with no abnormalities in sperm quality. Group 2 (G2) included those with demonstrated asthenozoospermia, while Group 3 (G3) were men with asthenoteratozoospermia. The remaining men with diagnosed oligoasthenoteratozoospermia, oligozoospermia, and teratozoospermia were included in Group 4 (G4).

Parallel to quality analysis, the total antioxidant capacity in semen (TAC-s) was assessed (the methodology was presented in the section Antioxidant Status).

\section{Antioxidant Status}

The measurement of total antioxidant capacity in semen (TAC-s) and blood serum (TAC-b) was based on the Trolox equivalent antioxidant capacity method (TEAC) and was determined using an assay kit (Randox Laboratories Ltd., UK). This colorimetric method allows to determine the capacity of a sample's antioxidants to inhibit ABTS+ $\bullet$ (radical monocation of 2,20-azinobis-3-ethylbenzothiazoline-6-sulphonic acid). The results were compared to the Trolox (soluble in water analog vitamin $\mathrm{E}$ ), which constitutes a reference antioxidant standard.

Ready-to-use kits (Randox Laboratories Ltd., UK) were used to determine superoxide dismutase (SOD-b) and glutathione reductase (GR-b) activity in the blood. For this purpose, the samples of EDTA whole blood were centrifuged $(10 \mathrm{~min}$ at $3,000 \mathrm{rpm}$ ) to separate plasma from erythrocytes. The received erythrocytes were washed four times with $0.9 \%$ $\mathrm{NaCl}$, diluted in $0.01 \mathrm{~mol} / \mathrm{l}$ phosphate buffer and incubated $\left(37^{\circ} \mathrm{C}\right)$ with xanthine oxidase and INT (2-(4-indophenyl)-5phenyltetrasodium chloride) to determine SOD-b activity, and with NADPH (nicotinamide adenine dinucleotide phosphate) to determine GR-b activity. Enzyme activity was determined spectrophotometrically (505 and $340 \mathrm{~nm}$, respectively) based on the degree of inhibition of this reaction (Multiskan Go, Thermo Scientific, USA).

Glutathione peroxidase (GPx-b) activity in the whole blood was determined using a RANSEL kit (Randox Laboratories Ltd., UK). The samples, diluted in Drabkin's reagent, were incubated at $37^{\circ} \mathrm{C}$ with cumene hydroperoxide. The decrease of absorbance over time was measured at $340 \mathrm{~nm}$ (MultiskanGo, Thermo Scientific, USA).

The level of decomposition of hydrogen peroxide (SigmaAldrich, US) was a measure of catalase activity in blood serum (CAT-b). The intensity of the colored complex formed by the mixture of purpald (4-amino-3-hydrazino-5-mercapto-1,2,4triazole measured) and formaldehyde (Sigma-Aldrich, US) was measured using the spectrophotometric method (wavelength of 340 nm, MultiskanGo, Thermo Scientific, USA) (40, 41).

To determine lipid peroxidation levels, the concentration of malondialdehyde (MDA) in blood serum was measured using the spectrophotometric method (wavelength of $530 \mathrm{~nm}$, MultiskanGo, Thermo Scientific, USA). This naturally occurring product of lipid peroxidation in reaction with thiobarbituric acid (TBA) at high temperatures $\left(90-100^{\circ} \mathrm{C}\right)$ formed a color complex-thiobarbituric acid-reactive substances (TBARS) $(42,43)$.

\section{Statistical Analysis}

Statistical analyses were performed using Statistica software (version 13.4, StatSoft, USA). The characteristics data were shown as mean values \pm standard deviation (SD) and as 
percentages of men by smoking status, alcohol consumption and supplements usage. The results were presented separately for four groups of men, which were created based on their semen quality (Figure 1).

The Chi-square test was used to determine statistically significant differences between categorical variables and groups of men with different semen quality. Based on the Shapiro-Wilks test, the hypothesis of normality of continuous variables was rejected; therefore, the Kruskal-Wallis and Mann-Whitney Utests were used to determine statistically significant differences between groups.

After transforming data $[\log (x)]$ to obtain normal distributions, Pearson correlation coefficients were used to determine associations between fruit and vegetable consumption and antioxidant status vs. the parameters of semen quality. Partial correlations were assessed to take into account the potential effect of the following parameters on the observed associations: age (years, continuous), BMI (<18.5, 18.5-24.9 and $>24.9 \mathrm{~kg} / \mathrm{m}^{2}$ ), sitting time (h/d, continuous), physical activity level (MET-h/week, continuous), smoking (ever, never), alcohol consumption (ever, never), supplement use (yes, no), wearing briefs and boxer shorts (ever, never), and energy intake (kcal/day, continuous).

Based on multivariate regression models adjusted for the same variables as partial correlations, antioxidant status and semen quality parameters were presented by quartiles of fruit and vegetable consumption (mean \pm standard error). The results with $P$-values of $\leq 0.05$ were admitted as statistically significant.

\section{RESULTS}

\section{Characteristics of the Studied Population}

The characteristics of the studied men by semen quality were presented in Table 1. Only 12\% of men had proper sperm quality. Asthenozoospermia was diagnosed in $43 \%$ of men, asthenoteratozoospermia in 35\%, while oligoasthenoteratozoospermia, oligozoospermia, or teratozoospermia were observed in the remaining 10\%. A statistically significantly higher consumption of fruit and vegetables was observed in men without abnormalities in sperm quality (G1) compared to the other groups of men (G2, G3, and G4). When fruit and vegetables were investigated separately, similar results were found for both fruit and vegetable consumption.

Significantly fewer men in the G2 group declared wearing briefs and boxer shorts than men in other groups. Men classified into different semen quality groups did not differ in terms of age, BMI, sleeping time, sitting time, physical activity, smoking status, alcohol consumption, supplement use, and energy intake. Moreover, no statistically significant differences in hemoglobin levels, analyzed hormones, and hsCRP were observed between the groups of men.

\section{Semen Quality and Antioxidant Status}

Semen analysis showed the highest average sperm concentration in the G1 group and a statistically significantly higher percentage of morphologically normal sperm in the G1 and G2 groups compared to other groups (Table 2). In the G1 and G2 groups, a significantly lower percentage of sperm head defects vs. the G3 and G4 groups were observed (88 and 91\% vs. 98 and $97 \%$, respectively). A significantly higher percentage of motile spermatozoa (total and progressive motility) was observed in the G1 and G4 groups than in the G2 and G3 groups. However, the groups of men did not differ statistically significantly in terms of sperm viability, the number of leucocytes in the ejaculate, and the percentage of sperm tail defects.

Moreover, in comparison to the groups of men with sperm abnormalities (G2, G3, and G4), the group of men with normozoospermia (G1) had the statistically significantly highest TAC levels in semen and blood as well as SOD-b activity (Table 3). The groups of men did not differ in terms of GPx-b, GR-b, CAT-b activities, and MDA-b concentration.

\section{Fruit and Vegetable Consumption in Relation to Antioxidant Status and Semen Quality Parameters}

The results of the Pearson correlation between fruit and vegetable consumption, antioxidant status, and selected semen quality parameters were shown in Table 4. The consumption of fruit and vegetables was statistically significantly positively correlated with sperm concentration $(r=0.30)$, vitality $(r=0.28)$, as well as total and progressive motility ( $r=0.38$ and 0.43 , respectively). Significant positive correlations were also found between the consumption of fruit and vegetables vs. TAC-s $(r=0.42)$, TAC-b $(r=0.28)$, and SOD-b activity $(r=0.29)$.

Moreover, the TAC-s and TAC-b were positively related to total and progressive motility (partial $r$ ranged from 0.22 to 0.35 ). The TAC-s was inversely correlated with sperm tail defects $(r=$ $-0.25)$. A positive correlation was found between SOD-b activity vs. vitality $(r=0.31)$, total and progressive motility $(r=0.46$ and 0.49 , respectively) and morphologically normal sperm $(r=$ $0.20)$. An inverse correlation of sperm tail defects $(r=-0.27)$ and leukocytes in ejaculate $(r=-0.27)$ with SOD-b activity were observed.

Based on multivariate regression models, adjusted means of antioxidant status parameters across the quartiles of fruit and vegetable consumption were estimated (Figure 2). Compared to the men in the lowest quartile of fruit and vegetable consumption $(<318 \mathrm{~g} /$ day $)$, the men in the highest quartile ( $>734 \mathrm{~g} /$ day $)$ had a higher mean of TAC-s (mean $\pm \mathrm{SE}, 0.95 \pm 0.03$ vs. $1.09 \pm 0.04$ $\mathrm{mmol} / \mathrm{l})$, TAC-b (1.48 \pm 0.04 vs. $1.60 \pm 0.04 \mathrm{mmol} / \mathrm{l}), \mathrm{GPx}-\mathrm{b}$ $(51.0 \pm 2.2$ vs. $60.5 \pm 2.1 \mathrm{U} / \mathrm{g} \mathrm{Hb})$, and a lower MDA-b (2.40 \pm 0.06 vs. $2.67 \pm 0.08 \mu \mathrm{mol} / \mathrm{ml})$. A trend to a higher mean of SOD-b in men with the highest compared to those with the lowest fruit and vegetable intake was found $(1,437 \pm 63$ vs. 1,265 \pm 43 $\mathrm{U} / \mathrm{g} \mathrm{Hb}$ ).

Using multivariate regression models, significant differences in selected semen quality parameters across the quartiles of fruit and vegetable consumption were shown (Figure 3). Compared to the men in the first quartile of fruit and vegetable consumption $(<318 \mathrm{~g} /$ day), the men in the highest quartile ( $>734 \mathrm{~g} /$ day) had a statistically significant higher sperm concentration $(55.6 \pm 6.7$ vs. $96.2 \pm 10.4 \times 106 / \mathrm{ml})$, vitality $(61.3 \pm 1.8$ vs. $64.9 \pm 1.8 \%$ 
TABLE 1 | Baseline characteristics of participants (mean \pm SD).

\begin{tabular}{|c|c|c|c|c|c|}
\hline Variables & $\mathrm{G1}(n=11)$ & G2 $(n=39)$ & G3 $(n=31)$ & G4 $(n=9)$ & $P$-value \\
\hline \multicolumn{6}{|l|}{ Consumption (g/day) } \\
\hline Fruit and vegetables & $874 \pm 321^{a}$ & $496 \pm 308^{b}$ & $554 \pm 290^{b}$ & $541 \pm 224^{b}$ & $0.007^{\star}$ \\
\hline Fruit & $445 \pm 258^{a}$ & $176 \pm 173^{b}$ & $193 \pm 191^{b}$ & $259 \pm 200^{b}$ & $0.016^{\star}$ \\
\hline Vegetables & $430 \pm 153^{a}$ & $320 \pm 201^{b}$ & $361 \pm 159^{a b}$ & $281 \pm 127^{b}$ & $0.050^{\star}$ \\
\hline Age (years) & $25.4 \pm 4.1$ & $28.3 \pm 5.6$ & $27.5 \pm 4.6$ & $27.1 \pm 3.2$ & $0.475^{\star}$ \\
\hline $\mathrm{BMI}\left(\mathrm{kg} / \mathrm{m}^{2}\right)$ & $23.7 \pm 2.7$ & $25.4 \pm 5.3$ & $24.8 \pm 3.7$ & $25.1 \pm 3.5$ & $0.661^{\star}$ \\
\hline Sleeping time (h/day) & $7.1 \pm 0.5$ & $7.2 \pm 0.8$ & $7.2 \pm 0.8$ & $7.1 \pm 1.0$ & $0.944^{*}$ \\
\hline Sitting time (h/day) & $9.3 \pm 2.2$ & $7.9 \pm 2.5$ & $8.0 \pm 2.3$ & $8.4 \pm 1.8$ & $0.301^{*}$ \\
\hline Physical activity (MET-h/week) & $112 \pm 52$ & $140 \pm 81$ & $146 \pm 66$ & $105 \pm 24$ & $0.221^{\star}$ \\
\hline Current smokers (\%) & 18 & 18 & 23 & 0 & $0.492^{\#}$ \\
\hline \multicolumn{6}{|l|}{ Alcohol consumption (\%) } \\
\hline >2-3 times/week & 91 & 87 & 87 & 100 & $0.712^{\#}$ \\
\hline$\leq 1$ times/week or never & 9 & 13 & 13 & 0 & \\
\hline Supplement use (\%) & 64 & 72 & 65 & 44 & $0.484^{\#}$ \\
\hline \multicolumn{6}{|l|}{ Type of underwear (\%) } \\
\hline Briefs and boxer shorts & $91^{\mathrm{a}}$ & $71^{b}$ & $97^{a}$ & $89^{a}$ & $0.032^{\#}$ \\
\hline Shorts & 9 & 29 & 3 & 11 & \\
\hline Energy intake (kcal/day) & $2,527 \pm 703$ & $2,417 \pm 586$ & $2,583 \pm 823$ & $2,340 \pm 492$ & 0.841 \\
\hline \multicolumn{6}{|l|}{ Blood analysis } \\
\hline Hemoglobin (g/dl) & $15.6 \pm 0.8$ & $15.5 \pm 0.8$ & $15.3 \pm 1.0$ & $15.4 \pm 0.7$ & $0.687^{\star}$ \\
\hline Total testosterone (ng/dl) & $564 \pm 118$ & $517 \pm 147$ & $529 \pm 201$ & $435 \pm 195$ & $0.243^{*}$ \\
\hline $\mathrm{FSH}(\mathrm{mlU} / \mathrm{ml})$ & $4.9 \pm 1.8$ & $5.6 \pm 2.0$ & $5.0 \pm 2.3$ & $5.3 \pm 1.7$ & $0.602^{\star}$ \\
\hline Prolactin (ng/dl) & $9.6 \pm 1.4$ & $9.1 \pm 2.8$ & $8.8 \pm 3.2$ & $9.9 \pm 2.3$ & $0.555^{\star}$ \\
\hline $\mathrm{hCRP}(\mathrm{mg} / \mathrm{dl})$ & $1.3 \pm 1.0$ & $1.5 \pm 1.9$ & $0.8 \pm 0.8$ & $0.7 \pm 0.3$ & $0.426^{\star}$ \\
\hline
\end{tabular}

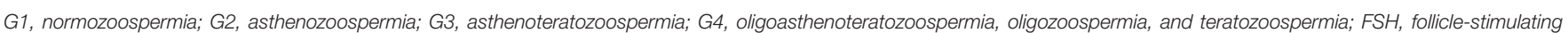

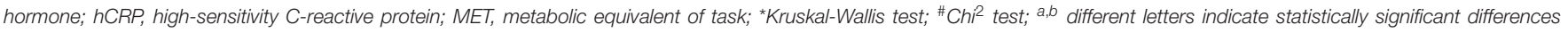
between a group, $p$-value $\leq 0.05$ (Mann-Whitney U-test). The results with P-values of $\leq 0.05$ were admitted as statistically significant and were marked in bold cursive.

TABLE 2 | Semen quality parameters (mean \pm SD).

\begin{tabular}{|c|c|c|c|c|c|}
\hline Variables & G1 $(n=11)$ & G2 $(n=39)$ & G3 $(n=31)$ & G4 $(n=9)$ & $P$-value* \\
\hline Sperm concentration $\left(\times 10^{6} / \mathrm{ml}\right)$ & $93.1 \pm 53.0^{a}$ & $82.9 \pm 61.4^{\mathrm{ab}}$ & $76.8 \pm 49.9^{b}$ & $33.2 \pm 48.4^{b}$ & 0.030 \\
\hline Leukocytes in ejaculate $\left(\times 10^{6} / \mathrm{ml}\right)$ & $0.2 \pm 0.1$ & $0.5 \pm 0.4$ & $0.5 \pm 0.3$ & $0.3 \pm 0.4$ & 0.183 \\
\hline Vitality (live spermatozoa, \%) & $79.4 \pm 6.9$ & $71.7 \pm 9.9$ & $74.1 \pm 9.1$ & $69.6 \pm 7.2$ & 0.087 \\
\hline Total motility (PR + NP, \%) & $55.5 \pm 7.3^{\mathrm{a}}$ & $28.1 \pm 10.0^{\mathrm{b}}$ & $27.5 \pm 11.0^{\mathrm{b}}$ & $48.2 \pm 16.3^{a}$ & $<0.001$ \\
\hline Progressive motility (\%) & $39.7 \pm 9.1^{\mathrm{a}}$ & $12.9 \pm 7.6^{b}$ & $10.9 \pm 7.0^{b}$ & $31.2 \pm 13.2^{a}$ & $<0.001$ \\
\hline Sperm morphology (normal forms, \%) & $10.4 \pm 6.0^{\mathrm{a}}$ & $7.9 \pm 3.1^{\mathrm{a}}$ & $1.9 \pm 1.3^{b}$ & $3.4 \pm 4.9^{b}$ & $<0.001$ \\
\hline Sperm head defects (\%) & $88.3 \pm 5.5^{\mathrm{a}}$ & $90.6 \pm 3.7^{a}$ & $97.7 \pm 1.7^{b}$ & $96.6 \pm 4.9^{b}$ & $<0.001$ \\
\hline Sperm tail defects (\%) & $5.9 \pm 3.7$ & $7.0 \pm 5.8$ & $8.6 \pm 7.1$ & $8.4 \pm 7.8$ & 0.730 \\
\hline
\end{tabular}

G1, normozoospermia; G2, asthenozoospermia; G3, asthenoteratozoospermia; G4, oligoasthenoteratozoospermia, oligozoospermia, and teratozoospermia; ${ }^{*}$ Kruskal-Wallis test; a,b

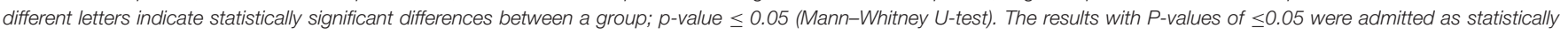
significant and were marked in bold cursive.

of live sperm), total motility $(23.8 \pm 2.7$ vs. $33.9 \pm 3.7 \%)$, and progressive motility ( $10.3 \pm 2.3$ vs. $21.0 \pm 3.6 \%)$.

\section{DISCUSSION}

To the best of our knowledge, this is the first study that has analyzed the associations of fruit and vegetable consumption with antioxidant status and semen quality and confirms relationships between these parameters.

In this study, a significantly higher consumption of fruit and vegetables in men with normal semen quality than men with abnormality cases was shown. Greater consumption of these products was related to higher sperm concentration, vitality as well as total and progressive semen motility. It should be emphasized that the relationships demonstrated in this study 
TABLE 3 | Antioxidant status parameters (mean $\pm \mathrm{SD}$ ).

\begin{tabular}{|c|c|c|c|c|c|}
\hline Variables & $\mathrm{G1}(n=11)$ & G2 $(n=39)$ & G3 $(n=31)$ & G4 $(n=9)$ & $P$-value* \\
\hline TAC-s (mmol/l) & $1.4 \pm 0.2^{a}$ & $1.2 \pm 0.2^{b}$ & $1.2 \pm 0.1^{b}$ & $1.1 \pm 0.2^{b}$ & 0.003 \\
\hline TAC-b (mmol/l) & $1.9 \pm 0.2^{a}$ & $1.7 \pm 0.2^{b}$ & $1.7 \pm 0.2^{b}$ & $1.7 \pm 0.1^{b}$ & 0.007 \\
\hline SOD-b (U/g Hb) & $1,827 \pm 88^{a}$ & $1,317 \pm 182^{b}$ & $1,338 \pm 201^{b}$ & $1,353 \pm 177^{b}$ & $<0.001$ \\
\hline GPx-b (U/g Hb) & $56.4 \pm 9.8$ & $49.6 \pm 11.6$ & $49.6 \pm 10.9$ & $51.9 \pm 10.7$ & 0.224 \\
\hline GR-b (U/g Hb) & $13.0 \pm 4.2$ & $12.9 \pm 3.9$ & $12.8 \pm 3.3$ & $11.7 \pm 2.6$ & 0.831 \\
\hline CAT-b (nmol/min/ml) & $14.2 \pm 2.1$ & $12.5 \pm 3.9$ & $13.1 \pm 2.6$ & $11.8 \pm 2.7$ & 0.418 \\
\hline MDA-b ( $\mu \mathrm{mol} / \mathrm{ml})$ & $2.5 \pm 0.4$ & $2.7 \pm 0.4$ & $2.6 \pm 0.3$ & $2.8 \pm 0.3$ & 0.102 \\
\hline
\end{tabular}

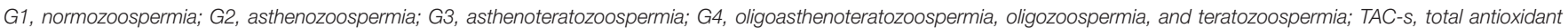

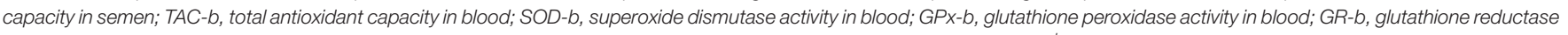

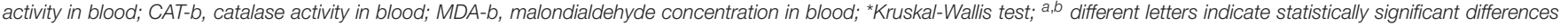
between a group; $p$-value $\leq 0.05$ (Mann-Whitney $U$-test). The results with P-values of $\leq 0.05$ were admitted as statistically significant and were marked in bold cursive.

were observed between the lowest vs. the highest quartiles of fruit and vegetable consumption, i.e., $<318$ vs. $>734$ g/day. As WHO recommends an intake of a minimum of $400 \mathrm{~g} /$ day of these products (44), it can be concluded that a higher consumption of fruit and vegetables may have a beneficial effect on semen quality.

Similar results were also shown in other studies but was, nevertheless, observed with a lower consumption of fruit and vegetables than in this study. A beneficial association of fruit consumption (2.33 servings/day, which corresponds to about 186 $\mathrm{g} /$ day if 1 serving $=80 \mathrm{~g}$ ) on total motility as well as consumption of legumes (3.63 servings/day, which corresponds to about 290 g/day) on sperm morphology was observed (26, 27). Moreover, in a case-control study including $241 \mathrm{men}$, the total fruit and vegetable consumption in the highest vs. lowest tertile (>522 vs. $<225 \mathrm{~g}$ /day) was related to a lower risk of asthenozoospermia (27). In other studies, a higher sperm concentration, total and progressive sperm motility, testosterone levels, and a lower DNA fragmentation index were associated with a pro-healthy dietary pattern (diet based on frequent consumption of i.a. fruit, vegetables, whole-grain products, legumes, and nuts) (2225). Additionally, the intake of antioxidants common in fruit and vegetables (such as vitamin $C$ and $\beta$-carotene) was related to a high total sperm count, motility, and low damage and fragmentation of sperm DNA, while a low intake of vitamin $\mathrm{C}$, lycopene and folate had a negative association with semen concentration and total motility (45). Moreover, based on intervention studies, it was concluded that vitamins $\mathrm{C}$ and $\mathrm{E}$ as well as folic acid may improve sperm concentration, motility, and morphology in infertile men $(18,19,46)$.

It is well-known that a balanced diet rich in antioxidant substances also plays an important role in the prooxidativeantioxidant balance of the body. The TAC level and antioxidant enzymes activity are significantly related to consumed food ingredients with antioxidant properties such as vitamin $\mathrm{C}, \mathrm{E}$, carotenes, polyphenols, and folate. In this study, the TAC in semen and blood and SOD activity in blood were positively associated with fruit and vegetable consumption. Moreover, the semen and blood TAC and GPx blood activity were highest in men characterized by the highest consumption of these products. Also, the lowest concentration of MDA in blood was observed in the same men. The results of intervention studies indicate that a higher consumption of antioxidant nutrients (polyphenols, alpha-lipoic acid, zinc, and folic acid) increased TAC levels in the blood and semen of infertile men (47-49). In another study, antioxidants intake with food and supplements (zinc, vitamin C, vitamin E, and folic acid) improved semen quality (lower level of sperm DNA damage) in 80 men with no reported fertility problem (50). Also, in animal studies, it was found that zinc supplementation increased SOD and GPx activity in the epididymis, liver and intestine and decreased lipid peroxidation levels in the epididymis of rats exposed to oxidative stress caused by high doses of iron $(51,52)$.

In the present study, higher semen and blood TAC as well as higher blood SOD activity in men with normozoospermia than in men with confirmed abnormalities in semen quality were observed. At the same time, TAC in both semen and blood was positively correlated with total and progressive sperm motility; TAC in semen was inversely correlated with sperm tail defects. Additionally, SOD activity in blood was positively related to vitality, total and progressive motility and morphology, and negatively correlated with the level of leukocytes in the ejaculate. The relationship between TAC level, antioxidant enzymes activity, and fertility were also observed by other authors. Men with astheno- and oligoasthenoteratozoospermia had a lower seminal TAC level and SOD activity compared to normozoospermic men (53-55). In the subfertile men, seminal but not blood TAC was lower than in men with idiopathic infertility (7). Furthermore, in a few studies, semen TAC was positively correlated with sperm concentration, total, and progressive motility as well as sperm morphology (lower percentage of abnormal sperm head and tail) $(7,56,57)$. Also, in the animal study, rats exposed to oxidative stress, induced by supplementing high doses of iron, had a lower percentage of live sperm, lower TAC in the prostate, lower SOD, and GPx activities in the epididymis as well as a higher concentration of MDA in the testes (51).

Considering the results of this study and other studies, the conclusion can be drawn that semen TAC can be used as a good biomarker to assess the redox status in semen and identify the defensive ability against oxidative stress of the male reproductive system. The determination of its level should be combined with the measurement of other parameters of semen 
TABLE 4 | Pearson correlation coefficients between fruit and vegetable consumption, antioxidant status and selected semen quality parameters ( $r, p)$.

\begin{tabular}{|c|c|c|c|c|c|c|c|c|c|c|c|c|c|c|c|c|}
\hline \multirow[t]{2}{*}{ Variables } & \multicolumn{2}{|c|}{$\begin{array}{c}\text { Fruit and } \\
\text { vegetable } \\
\text { consumption } \\
\text { (g/day) }\end{array}$} & \multicolumn{2}{|c|}{ TAC-s (mmol/l) } & \multicolumn{2}{|c|}{ TAC-b (mmol/l) } & \multicolumn{2}{|c|}{ SOD-b (U/g Hb) } & \multicolumn{2}{|c|}{ GPx-b (U/g Hb) } & \multicolumn{2}{|c|}{ GR-b (U/g Hb) } & \multicolumn{2}{|c|}{ CAT-b (nmol/min/ml) } & \multicolumn{2}{|c|}{ MDA-b $(\mu \mathrm{mol} / \mathrm{ml})$} \\
\hline & Crude & Partial $^{*}$ & Crude & Partial $^{\star}$ & Crude & Partial $^{\star}$ & Crude & Partial $^{*}$ & Crude & Partial ${ }^{\star}$ & Crude & Partial $^{\star}$ & Crude & Partial $^{\star}$ & Crude & Partial $^{*}$ \\
\hline $\begin{array}{l}\text { Fruit and } \\
\text { vegetable } \\
\text { consumption } \\
\text { (g/day) }\end{array}$ & - & - & $\begin{array}{c}0.36 \\
p<0.001\end{array}$ & $\begin{array}{c}0.42 \\
p<0.001\end{array}$ & $\begin{array}{c}0.25 \\
p=0.02\end{array}$ & $\begin{array}{c}0.28 \\
p=0.01\end{array}$ & $\begin{array}{c}0.27 \\
p=0.01\end{array}$ & $\begin{array}{c}0.29 \\
p=0.01\end{array}$ & $\begin{array}{c}0.13 \\
p=0.24\end{array}$ & $\begin{array}{c}0.12 \\
p=0.29\end{array}$ & $\begin{array}{c}0.05 \\
p=0.65\end{array}$ & $\begin{array}{c}0.02 \\
p=0.86\end{array}$ & $\begin{array}{c}0.14 \\
p=0.18\end{array}$ & $\begin{array}{c}0.17 \\
p=0.14\end{array}$ & $\begin{array}{c}-0.17 \\
p=0.13\end{array}$ & $\begin{array}{c}-0.16 \\
p=0.18\end{array}$ \\
\hline $\begin{array}{l}\text { Sperm } \\
\text { concentration } \\
\left(\times 10^{6} / \mathrm{ml}\right)\end{array}$ & $\begin{array}{c}0.28 \\
p=0.01\end{array}$ & $\begin{array}{c}0.30 \\
p=0.02\end{array}$ & $\begin{array}{c}0.00 \\
p=0.99\end{array}$ & $\begin{array}{c}0.01 \\
p=0.96\end{array}$ & $\begin{array}{c}-0.04 \\
p=0.75\end{array}$ & $\begin{array}{c}-0.04 \\
p=0.75\end{array}$ & $\begin{array}{c}0.08 \\
p=0.44\end{array}$ & $\begin{array}{c}0.11 \\
p=0.35\end{array}$ & $\begin{array}{c}0.05 \\
p=0.65\end{array}$ & $\begin{array}{c}0.44 \\
p=0.60\end{array}$ & $\begin{array}{c}0.08 \\
p=0.48\end{array}$ & $\begin{array}{c}0.03 \\
p=0.79\end{array}$ & $\begin{array}{c}0.03 \\
p=0.76\end{array}$ & $\begin{array}{c}0.09 \\
p=0.45\end{array}$ & $\begin{array}{c}-0.04 \\
p=0.74\end{array}$ & $\begin{array}{c}-0.04 \\
p=0.74\end{array}$ \\
\hline $\begin{array}{l}\text { Leukocytes in } \\
\text { ejaculate } \\
\left(\times 10^{6} / \mathrm{ml}\right)\end{array}$ & $\begin{array}{c}-0.07 \\
p=0.49\end{array}$ & $\begin{array}{c}-0.05 \\
p=0.67\end{array}$ & $\begin{array}{c}0.13 \\
p=0.22\end{array}$ & $\begin{array}{c}0.13 \\
p=0.27\end{array}$ & $\begin{array}{c}-0.09 \\
p=0.44\end{array}$ & $\begin{array}{c}-0.11 \\
p=0.36\end{array}$ & $\begin{array}{c}-0.22 \\
p=0.04\end{array}$ & $\begin{array}{c}-0.27 \\
p=0.02\end{array}$ & $\begin{array}{c}-0.09 \\
p=0.37\end{array}$ & $\begin{array}{c}-0.18 \\
p=0.12\end{array}$ & $\begin{array}{c}0.06 \\
p=0.59\end{array}$ & $\begin{array}{c}0.08 \\
p=0.49\end{array}$ & $\begin{array}{c}-0.08 \\
p=0.46\end{array}$ & $\begin{array}{c}-0.11 \\
p=0.36\end{array}$ & $\begin{array}{c}0.02 \\
p=0.83\end{array}$ & $\begin{array}{c}0.04 \\
p=0.72\end{array}$ \\
\hline $\begin{array}{l}\text { Vitality } \\
\text { (live spermatozoa, } \\
\% \text { ) }\end{array}$ & $\begin{array}{c}0.25 \\
p=0.02\end{array}$ & $\begin{array}{c}0.28 \\
p=0.01\end{array}$ & $\begin{array}{c}0.17 \\
p=0.11\end{array}$ & $\begin{array}{c}0.17 \\
p=0.14\end{array}$ & $\begin{array}{c}0.11 \\
p=0.30\end{array}$ & $\begin{array}{c}0.06 \\
p=0.61\end{array}$ & $\begin{array}{c}0.28 \\
p=0.007\end{array}$ & $\begin{array}{c}0.31 \\
p=0.007\end{array}$ & $\begin{array}{c}-0.09 \\
p=0.40\end{array}$ & $\begin{array}{c}-0.11 \\
p=0.35\end{array}$ & $\begin{array}{c}0.11 \\
p=0.33\end{array}$ & $\begin{array}{c}0.16 \\
p=0.18\end{array}$ & $\begin{array}{c}0.02 \\
p=0.86\end{array}$ & $\begin{array}{c}-0.02 \\
p=0.90\end{array}$ & $\begin{array}{c}-0.04 \\
p=0.74\end{array}$ & $\begin{array}{c}-0.18 \\
p=0.12\end{array}$ \\
\hline $\begin{array}{l}\text { Total motility (PR + } \\
\text { NP, \%) }\end{array}$ & $\begin{array}{c}0.35 \\
p<0.001\end{array}$ & $\begin{array}{c}0.38 \\
p=0.001\end{array}$ & $\begin{array}{c}0.36 \\
p=0.001\end{array}$ & $\begin{array}{c}0.32 \\
p=0.005\end{array}$ & $\begin{array}{c}0.21 \\
p=0.04\end{array}$ & $\begin{array}{c}0.22 \\
p=0.05\end{array}$ & $\begin{array}{c}0.51 \\
p<0.001\end{array}$ & $\begin{array}{c}0.46 \\
p<0.001\end{array}$ & $\begin{array}{c}0.03 \\
p=0.78\end{array}$ & $\begin{array}{c}0.02 \\
p=0.88\end{array}$ & $\begin{array}{c}-0.005 \\
p=0.96\end{array}$ & $\begin{array}{c}0.03 \\
p=0.81\end{array}$ & $\begin{array}{c}0.09 \\
p=0.41\end{array}$ & $\begin{array}{c}0.09 \\
p=0.44\end{array}$ & $\begin{array}{c}-0.19 \\
p=0.09\end{array}$ & $\begin{array}{c}-0.20 \\
p=0.08\end{array}$ \\
\hline $\begin{array}{l}\text { Progressive } \\
\text { motility } \\
(\%)\end{array}$ & $\begin{array}{c}0.41 \\
p<0.001\end{array}$ & $\begin{array}{c}0.43 \\
p<0.001\end{array}$ & $\begin{array}{c}0.37 \\
p<0.001\end{array}$ & $\begin{array}{c}0.35 \\
p=0.002\end{array}$ & $\begin{array}{c}0.25 \\
p=0.02\end{array}$ & $\begin{array}{c}0.27 \\
p=0.02\end{array}$ & $\begin{array}{c}0.57 \\
p<0.001\end{array}$ & $\begin{array}{c}0.49 \\
p<0.001\end{array}$ & $\begin{array}{c}-0.004 \\
p=0.97\end{array}$ & $\begin{array}{c}-0.007 \\
p=0.95\end{array}$ & $\begin{array}{c}-0.03 \\
p=0.78\end{array}$ & $\begin{array}{c}-0.08 \\
p=0.50\end{array}$ & $\begin{array}{c}0.09 \\
p=0.43\end{array}$ & $\begin{array}{c}0.11 \\
p=0.33\end{array}$ & $\begin{array}{c}-0.09 \\
p=0.42\end{array}$ & $\begin{array}{c}-0.09 \\
p=0.43\end{array}$ \\
\hline $\begin{array}{l}\text { Sperm } \\
\text { morphology } \\
\text { (normal forms, \%) }\end{array}$ & $\begin{array}{c}0.02 \\
p=0.89\end{array}$ & $\begin{array}{c}0.02 \\
p=0.83\end{array}$ & $\begin{array}{c}0.04 \\
p=0.73\end{array}$ & $\begin{array}{c}0.09 \\
p=0.44\end{array}$ & $\begin{array}{c}-0.01 \\
p=0.94\end{array}$ & $\begin{array}{c}-0.04 \\
p=0.76\end{array}$ & $\begin{array}{c}0.22 \\
p=0.03\end{array}$ & $\begin{array}{c}0.20 \\
p=0.05\end{array}$ & $\begin{array}{c}0.07 \\
p=0.53\end{array}$ & $\begin{array}{c}0.09 \\
p=0.41\end{array}$ & $\begin{array}{c}-0.09 \\
p=0.44\end{array}$ & $\begin{array}{c}-0.15 \\
p=0.19\end{array}$ & $\begin{array}{c}-0.12 \\
p=0.27\end{array}$ & $\begin{array}{c}-0.08 \\
p=0.50\end{array}$ & $\begin{array}{c}-0.01 \\
p=0.93\end{array}$ & $\begin{array}{c}0.02 \\
p=0.86\end{array}$ \\
\hline $\begin{array}{l}\text { Sperm head } \\
\text { defects (\%) }\end{array}$ & $\begin{array}{c}-0.01 \\
p=0.93\end{array}$ & $\begin{array}{c}0.01 \\
p=0.96\end{array}$ & $\begin{array}{c}-0.02 \\
p=0.84\end{array}$ & $\begin{array}{c}-0.05 \\
p=0.67\end{array}$ & $\begin{array}{c}-0.02 \\
p=0.85\end{array}$ & $\begin{array}{c}0.02 \\
p=0.88\end{array}$ & $\begin{array}{c}-0.20 \\
p=0.06\end{array}$ & $\begin{array}{c}-0.19 \\
p=0.10\end{array}$ & $\begin{array}{c}-0.14 \\
p=0.21\end{array}$ & $\begin{array}{c}-0.16 \\
p=0.17\end{array}$ & $\begin{array}{c}0.02 \\
p=0.87\end{array}$ & $\begin{array}{c}0.05 \\
p=0.69\end{array}$ & $\begin{array}{c}0.10 \\
p=0.36\end{array}$ & $\begin{array}{c}0.07 \\
p=0.54\end{array}$ & $\begin{array}{c}-0.04 \\
p=0.32\end{array}$ & $\begin{array}{c}0.01 \\
p=0.98\end{array}$ \\
\hline $\begin{array}{l}\text { Sperm tail defects } \\
(\%)\end{array}$ & $\begin{array}{c}-0.09 \\
p=0.39\end{array}$ & $\begin{array}{c}-0.14 \\
p=0.23\end{array}$ & $\begin{array}{c}-0.24 \\
p=0.03\end{array}$ & $\begin{array}{c}-0.25 \\
p=0.03\end{array}$ & $\begin{array}{c}-0.07 \\
p=0.54\end{array}$ & $\begin{array}{c}-0.06 \\
p=0.61\end{array}$ & $\begin{array}{c}-0.25 \\
p=0.02\end{array}$ & $\begin{array}{c}-0.27 \\
p=0.02\end{array}$ & $\begin{array}{c}0.05 \\
p=0.67\end{array}$ & $\begin{array}{c}0.05 \\
p=0.65\end{array}$ & $\begin{array}{c}0.01 \\
p=0.99\end{array}$ & $\begin{array}{c}-0.06 \\
p=0.58\end{array}$ & $\begin{array}{c}-0.12 \\
p=0.27\end{array}$ & $\begin{array}{c}-0.15 \\
p=0.19\end{array}$ & $\begin{array}{c}-0.06 \\
p=0.84\end{array}$ & $\begin{array}{c}0.04 \\
p=0.43\end{array}$ \\
\hline
\end{tabular}

*In contrast to the crude (not adjusted) the partial correlation coefficients were adjusted for age (years, continuous), BMI (<18.5, 18.5-24.9, and >24.9, $\left.\mathrm{kg} / \mathrm{m}^{2}\right)$, sitting time (h/d, continuous), physical activity level (MET-h/week, continuous), smoking (ever, never), alcohol consumption (ever, never), supplement use (yes, no), wearing briefs and short boxer (ever, never), and energy (kcal/d, continuous); TAC-s, total antioxidant capacity in semen; TAC-b, total antioxidant capacity in blood; TAC-s, total antioxidant capacity in semen; TAC-b, total antioxidant capacity in blood; SOD-b, superoxide dismutase activity in blood; GPx-b, glutathione peroxidase activity in blood; GR-b, glutathione reductase activity in blood; CAT-b, catalase activity in blood; MDA-b, malondialdehyde concentration in blood; PR, progressive motility; NP, non-progressive motility. The results with $P$-values of $\leq 0.05$ were admitted as statistically significant and were marked in bold cursive. 


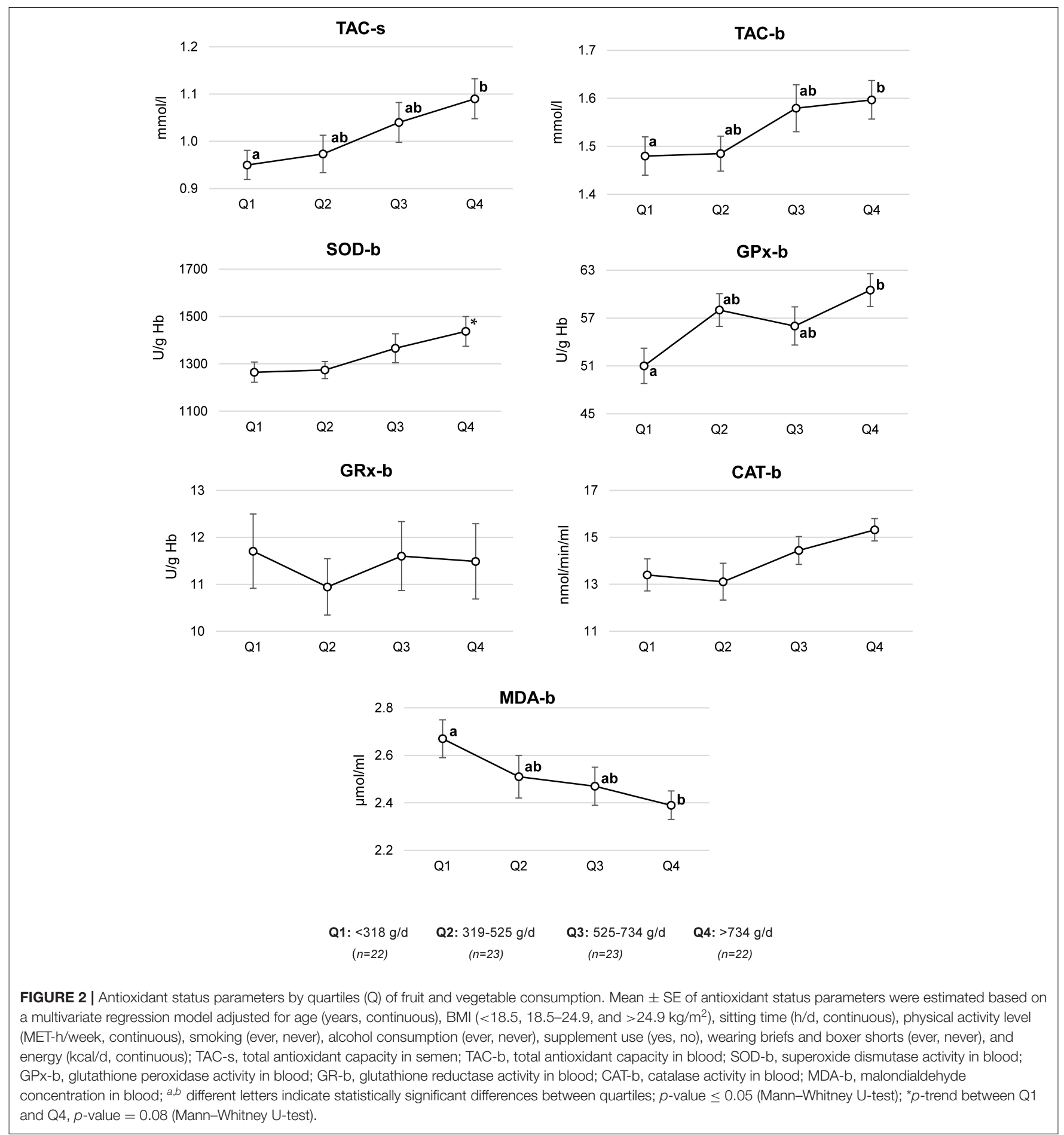

quality. Moreover, TAC assessment in male infertility may justify nutritional intervention based on increasing antioxidant intake as therapy for some patients (58).

Moreover, fruit and vegetables are one of the main sources of fiber in a diet. It has been shown that dietary fiber may have a beneficial effect on reducing oxidative stress in the body by participating in the assimilation of antioxidants in the intestine present in fruit and vegetables, such as polyphenols and carotenoids $(20,21)$. Increased dietary fiber consumption also positively impacts the gut microbiome, which plays a key role in the immune system's function and reduces the concentration of pro-inflammatory mediators such as IL-6 and CRP $(59,60)$. However, the effect of dietary fiber consumption on estrogen and testosterone concentration is not fully understood (30-34). 

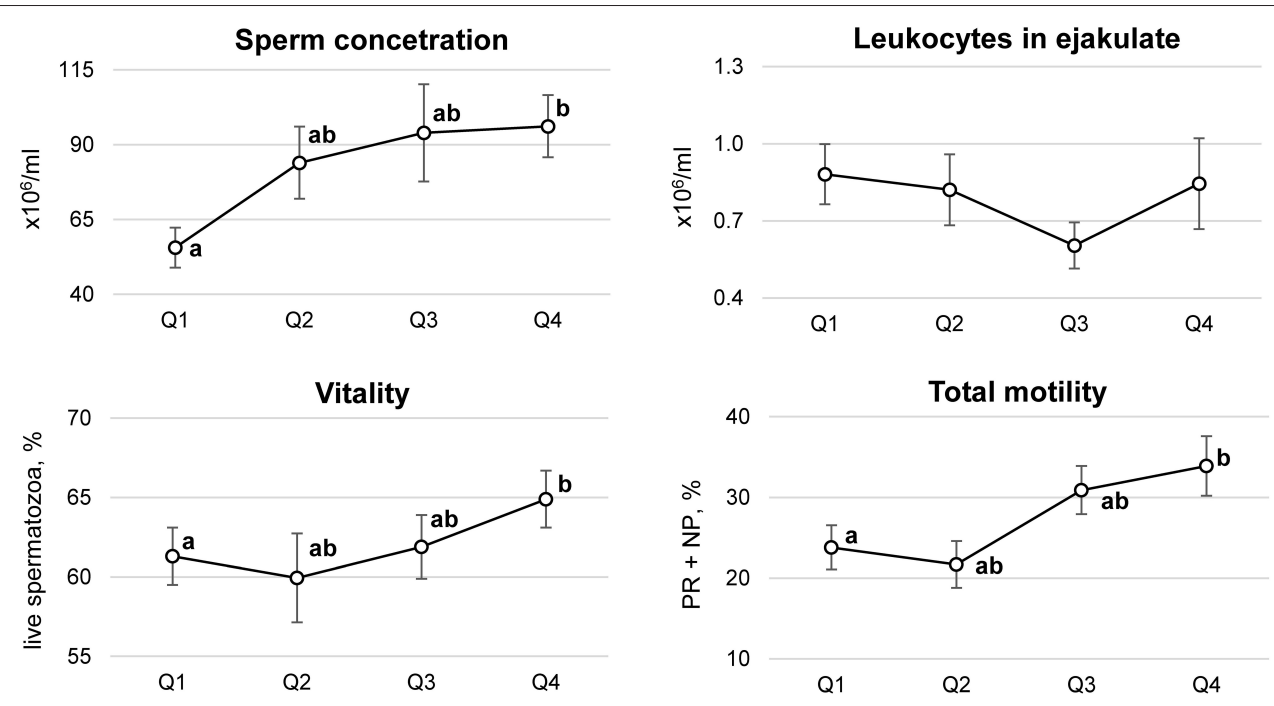

Progressive motility
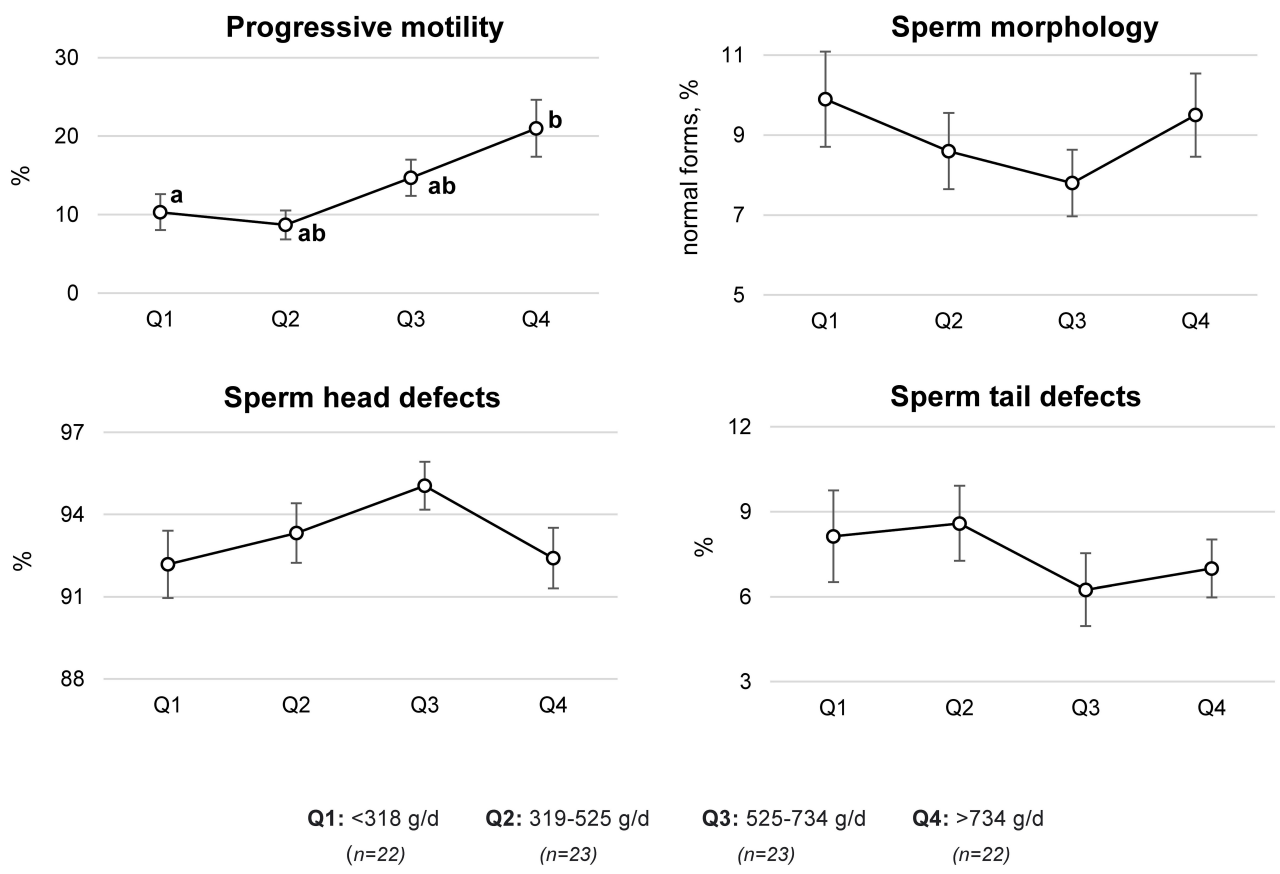

$\begin{array}{cc}\text { Q3: } 525-734 \mathrm{~g} / \mathrm{d} & \text { Q4: }>\text { 734 } \mathrm{g} / \mathrm{d} \\ (n=23) & (n=22)\end{array}$

FIGURE 3 | Semen quality parameters by quartiles (Q) of fruit and vegetable consumption. Mean \pm SE of semen quality parameters were estimated based on a multivariate regression model adjusted for age (years, continuous), BMl (<18.5, 18.5-24.9, and $>24.9 \mathrm{~kg} / \mathrm{m}^{2}$ ), sitting time (h/d, continuous), physical activity level (MET-h/week, continuous), smoking (ever, never), alcohol consumption (ever, never), supplement use (yes, no), wearing briefs and boxer shorts (ever, never), and energy (kcal/d, continuous). PR, progressive motility; NP, non-progressive motility; ${ }^{a, b}$ different letters indicate statistically significant differences between quartiles, $p$-value $\leq 0.05$ (Mann-Whitney U-test).

Although most studies have shown a positive role of fruit and vegetable consumption on male sperm quality, in several of them, no such beneficial associations were observed. Their consumption was not related to any sperm quality indicators (sperm concentration, progressive motility, and sperm morphology) in 188 healthy men aged 18-22 (61). Also, the results of other studies show no associations between a prohealthy dietary pattern (frequent consumption of i.a. fruit, vegetables, whole-grain products, legumes, and nuts) and semen quality $(28,29)$. It is worth noting that vegetables and fruit may contain pesticide residue and/or be contaminated with heavy metals. It has been shown that the consumption of fruit and vegetables with high pesticide residue (but not with low or moderate residue) was associated with a lower percentage of morphologically normal sperm and total sperm motility as well as the deterioration of semen antioxidant status $(26,35,45,62)$. Pesticides, including organophosphates, bipyridyl herbicides, and organochlorine, may stimulate an increased production of ROS as well as induce lipid peroxidation and reduce total antioxidant levels in the blood (63). Also, the results of animal 
and human studies confirm that heavy metals have a negative effect on semen and the male reproductive system $(36,64)$. Additionally, raw vegetables are the main nitrate source in a usual diet (about 80\%) (65). The European Food Safety Authority reported that nitrate, after converting to nitrite (during storage or by oral bacteria and enzymes in salivary), might cause adverse health effects (66). Whereas, in a systematic review including animal studies, a negative effect of the intake of nitrate with water on semen quality parameters was observed (37).

It is also worth noting that some of the investigated semen parameters (sperm morphology and leukocytes in the ejaculate) were not related to the consumption of fruit and vegetables in our study. Independently from antioxidant dietary intake, morphological sperm damage could be generated by other factors like genetic, enzymatic, or ROS-related factors during spermatogenesis $(3,5)$.

The role and potential mechanisms of some non-dietary lifestyle factors on semen quality are still inconsistent. In this study, we did not observe any differences among groups of men in terms of age, BMI, sleeping time, sitting time, physical activity, smoking status, alcohol consumption, supplement use, and energy intake. Also, in some studies, the impact of sleep duration $(67)$ or physical activity $(68,69)$ on semen quality was not shown. However, associations between physical activity as well as a sedentary life-style and semen quality in other studies have been found $(70,71)$.

The strength of the study was the use of the 3-day food record method to collect data about food consumption and assess fruit and vegetable consumption. A qualified interviewer accurately checked the returned questionnaires, and possible missing or imprecise information about the food consumed and portion sizes were completed. Also, this method is not based on the respondents' memory, thus it is free from recall bias. Since data was collected in the early spring and autumn, some restrictions in access to certain fruit and vegetables may have potentially affected their consumption. Another limitation of this study is the number of studied men and that they were not randomly selected but volunteered to participate in the study. However, they were qualified based on strict inclusion and exclusion criteria. Moreover, because of the cross-sectional design of the study, it cannot be predicted if increasing fruit and vegetable consumption has a beneficial effect on antioxidant status and sperm quality but the indicated interrelations might for a basis for intervention in further studies. Also, only one semen sample was analyzed; nonetheless, some authors have shown that one sample is sufficient to assess the quality of semen in epidemiological studies (72).

\section{REFERENCES}

1. Agarwal A, Mulgund A, Hamada A, Chyatte MR. A unique view on male infertility around the globe. Reprod Biol Endocrinol. (2015) 26:13-37. doi: 10.1186/s12958-015-0032-1

2. Jungwirth A, Giwercman A, Tournaye H, Diemer T, Kopa Z, Dohle G, et al. European Association of Urology guidelines on male infertility:

\section{CONCLUSIONS}

In summary, the results indicate that high fruit and vegetable consumption may be positively associated with semen quality, and this relationship seems to be involved in antioxidant status underlying the etiology of sperm quality disorders. Taking into account the results of this study and the results of other authors, it can be concluded that the nutritional strategy based on a high consumption of fruit and vegetables to prevent and treat infertility by improving the redox status should be analyzed in future clinical studies.

\section{DATA AVAILABILITY STATEMENT}

The raw data supporting the conclusions of this article will be made available by the authors, without undue reservation.

\section{ETHICS STATEMENT}

The studies involving human participants were reviewed and approved by the Ethical Committee at the Institute of Human Nutrition Sciences, Warsaw University of Life Sciences (N08/2016) and has been performed in accordance with the ethical standards laid down in the 1964 Declaration of Helsinki and its later amendments. The patients/participants provided their written informed consent to participate in this study.

\section{AUTHOR CONTRIBUTIONS}

DM: conceptualization, methodology, formal analysis, investigation, and writing-original draft. DG, ES and, JK: writing-review and editing and visualization. All authors have read and agreed to the published version of the manuscript.

\section{FUNDING}

The study was supported by a grant from the National Science Center (NCN), Poland (No. 2018/02/X/NZ9/01103). The research for this study was carried out with the use of research equipment purchased as part of the Food and Nutrition Center-modernization of the WULS campus to create a Food and Nutrition Research and Development Center (CZiZ) co-financed by the European Union from the European Regional Development Fund under the Regional Operational Programme of the Mazowieckie Voivodeship for 2014-2020 (Project No. RPMA.01.01.00-14-8276/17). 
sperm parameters and sperm DNA fragmentation (SDF) measured by Halosperm((R)). Arch Gynecol Obstet. (2014) 290:777-82. doi: 10.1007/s00404-014-3281-x

5. Aitken RJ, Baker MA. Oxidative stress, sperm survival and fertility control. Mol and Cell Endocrinol. (2006) 250:66-9. doi: 10.1016/j.mce.2005.12.026

6. Ko EY, Sabanegh ES, Agarwal A. Male infertility testing: reactive oxygen species and antioxidant capacity. Fertil Steril. (2014) 102:1518-27. doi: 10.1016/j.fertnstert.2014.10.020

7. Subramanian V, Ravichandran A, Thiagarajan N, Govindarajan M, Dhandayuthapani S, Suresh S. Seminal reactive oxygen species and total antioxidant capacity: correlations with sperm parameters and impact on male infertility. Clin Exp Reprod Med. (2018) 45:88-93. doi: 10.5653/cerm.2018.45.2.88

8. Bahmyari R, Zare M, Sharma R, Agarwal A, Halvaei I. The efficacy of antioxidants in sperm parameters and production of reactive oxygen species levels during the freeze-thaw process: a systematic review and meta-analysis. Andrologia. (2020) 52:89-102. doi: 10.1111/and.13514

9. Agarwal A, Mulgund A, Alshahrani S, Assidi M, Abuzenadah AM, Sharma $\mathrm{R}$, et al. Reactive oxygen species and sperm DNA damage in infertile men presenting with low level leukocytospermia. Reprod Biol Endocrin. (2014) 12:1-8. doi: 10.1186/1477-7827-12-126

10. Aitken RJ, Krausz C. Oxidative stress, DNA damage and the Y chromosome. Reproduction. (2001) 122:497-506. doi: 10.1530/rep.0.1220497

11. Ben Abdallah F, Dammak I, Attia H, Hentati B, Ammar-Keskes L. Lipid peroxidation and antioxidant enzyme activities in infertile men: correlation with semen parameter. J Clin Lab Anal. (2009) 23:99-104. doi: $10.1002 /$ jcla.20297

12. Takhshid MA, Tavasuli AR, Heidary Y, Keshavarz M, Kargar H. Protective effect of vitamins $\mathrm{E}$ and $\mathrm{C}$ on endosulfan-induced reproductive toxicity in male rats. Iran Jour Med Sci. (2012) 37:173-80.

13. Aitken RJ, Jones KT, Robertson SA. Reactive oxygen species and sperm function-in sickness and in health. J Androl. (2012) 33:1096-106. doi: 10.2164/jandrol.112.016535

14. Ross C, Morriss A, Khairy M, Khalaf Y, Braude P, Coomarasamy A, et al. systematic review of the effect of oral antioxidants on male infertility. Reprod Biomed Online. (2010) 20:711-23. doi: 10.1016/j.rbmo.2010.03.008

15. Showell MG, Mackenzie-Proctor R, Brown J, Yazdani A, Stankiewicz MT, Hart RJ. Antioxidants for male subfertility. Cochrane Database Syst Rev. (2014) 12:234-51. doi: 10.1002/14651858.CD007411.pub3

16. Young SS, Eskenazi B, Marchetti FM, Block G, Wyrobek AJ. The association of folate, zinc and antioxidant intake with sperm aneuploidy in healthy nonsmoking men. Hum Reprod. (2008) 23:1014-22. doi: 10.1093/humrep/den036

17. Busetto GM, Del Giudice F, Virmani A, Sciarra A, Maggi M, Ferro M, et al. Body mass index and age correlate with antioxidant supplementation effects on sperm quality: Post hoc analyses from a double-blind placebo-controlled trial. Andrologia. (2020) 52:135-88. doi: 10.1111/and.13523

18. Wong WY, Merkus HM, Thomas CM, Menkveld R, Zielhuis GA, SteegersTheunissen RP. Effects of folic acid and zinc sulfate on male factor subfertility: a double-blind, randomized, placebo-controlled trial. Fertil Steril. (2002) 77:491-8. doi: 10.1016/s0015-0282(01)03229-0

19. Keskes-Ammar L, Feki-Chakroun N, Rebai T, Sahnoun Z, Ghozzi H, Hammami S, et al. Sperm oxidative stress and the effect of an oral vitamin $\mathrm{E}$ and selenium supplement on semen quality in infertile men. Arch Andrology. (2003) 49:83-94. doi: 10.1080/713828100

20. Saura-Calixto F. Dietary fiber as a carrier of dietary antioxidants: an essential physiological function. J Agr Food Chem. (2011) 59:43-9. doi: $10.1021 /$ jf1036596

21. Palafox-Carlos H, Ayala-Zavala JF, Gonzalez-Aguilar GA. The role of dietary fiber in the bioaccessibility and bioavailability of fruit and vegetable antioxidants. J Food Sci. (2011) 76:6-15. doi: 10.1111/j.1750-3841.2010.01957.x

22. Cutillas-Tolin A, Minguez-Alarcon L, Mendiola J, Lopez-Espin JJ, Jorgensen $\mathrm{N}$, Navarrete-Munoz EM, et al. Mediterranean and western dietary patterns are related to markers of testicular function among healthy men. Hum Reprod. (2015) 30:2945-55. doi: 10.1093/humrep/dev236

23. Oostingh EC, Steegers-Theunissen RPM, de Vries JHM, Laven JSE, Koster $\mathrm{MPH}$. Strong adherence to a healthy dietary pattern is associated with better semen quality, especially in men with poor semen quality. Fertil Steril. (2017) 107:542-62. doi: 10.1016/j.fertnstert.2017.02.103

24. Karayiannis D, Kontogianni MD, Mendorou C, Douka L, Mastrominas M, Yiannakouris N. Association between adherence to the Mediterranean diet and semen quality parameters in male partners of couples attempting fertility. Hum Reprod. (2017) 32:215-22. doi: 10.1093/humrep/dew288

25. Jurewicz J, Radwan M, Sobala W, Radwan P, Bochenek M, Hanke W. Dietary patterns and their relationship with semen quality. Am J Mens Health. (2018) 12:575-83. doi: 10.1177/1557988315627139

26. Braga DP, Halpern G, Figueira Rde C, Setti AS, Iaconelli A, Borges E. Food intake and social habits in male patients and its relationship to intracytoplasmic sperm injection outcomes. Fertil Steril. (2012) 97:53-9. doi: 10.1016/j.fertnstert.2011.10.011

27. Eslamian G, Amirjannati N, Rashidkhani B, Sadeghi MR, Hekmatdoost A. Intake of food groups and idiopathic asthenozoospermia: a case-control study. Hum Reprod. (2012) 27:3328-36. doi: 10.1093/humrep/des311

28. Danielewicz A, Przybylowicz KE, Przybylowicz M. Dietary patterns and poor semen quality risk in men: a cross-sectional study. Nutrients. (2018) 10:1162. doi: 10.3390/nu10091162

29. Liu CY, Chou YC, Chao JCJ, Hsu CY, Cha TL, Tsao CW. The association between dietary patterns and semen quality in a general asian population of 7282 males. PLos ONE. (2015) 10. doi: 10.1371/journal.pone.0134224

30. Maheshwari A, Verma N, Swaroop A, Bagchi M, Preuss HG, Tiwari K, et al. Efficacy of Furosap(TM), a novel Trigonella foenum-graecum seed extract, in enhancing testosterone level and improving sperm profile in male volunteers. Int J Med Sci. (2017) 14:58-66. doi: 10.7150/ijms.17256

31. Greenlee H, Atkinson C, Stanczyk FZ, Lampe JW. A pilot and feasibility study on the effects of naturopathic botanical and dietary interventions on sex steroid hormone metabolism in premenopausal women. Cancer Epidemiol. Biomarkers Prev. (2007) 16:1601-9. doi: 10.1158/1055-9965.EPI-06-0938

32. Slavin JL. Position of the American Dietetic Association: health implications of dietary fiber. J Am Diet Assoc. (2008) 108:1716-31. doi: 10.1016/j.jada.2008.08.007

33. Dorgan JF, Judd JT, Longcope C, Brown C, Schatzkin A, Clevidence BA, et al. Effects of dietary fat and fiber on plasma and urine androgens and estrogens in men: a controlled feeding study. Am J Clin Nutr. (1996) 64:850-5. doi: $10.1093 /$ ajcn/64.6.850

34. Rambhatla A, Mills JN, Rajfer J. The role of estrogen modulators in male hypogonadism and infertility. Rev Urol. (2016) 18:66-72. doi: 10.3909/ riu0711

35. Chiu YH, Afeiche MC, Gaskins AJ, Williams PL, Petrozza JC, Tanrikut C, et al. Fruit and vegetable intake and their pesticide residues in relation to semen quality among men from a fertility clinic. Hum Reprod. (2015) 30:1342-51. doi: 10.1093/humrep/dev064

36. Heidari AH, Zamiri MJ, Nazem MN, Jafarzadeh Shirazi MR, Akhlaghi A, Ansari Pirsaraei Z. Detrimental effects of long-term exposure to heavy metals on histology, size and trace elements of testes and sperm parameters in Kermani Sheep. Ecotox Environ Safe. (2021) 207:541-63. doi: 10.1016/j.ecoenv.2020.111563

37. Clausen HS, Ebdrup NH, Barsoe IM, Lyngso J, Schullehner J, RamlauHansen $\mathrm{CH}$, et al. Association between drinking water nitrate and adverse reproductive outcomes: a systematic PRISMA review. Water. (2020) 12:2287. doi: 10.3390/W12082287

38. Craig CL, Marshall AL, Sjostrom M, Bauman AE, Booth ML, Ainsworth $\mathrm{BE}$, et al. International physical activity questionnaire: 12-country reliability and validity. Med Sci Sport Exer. (2003) 35:1381-95. doi: 10.1249/01.MSS.0000078924.61453.FB

39. World Health Organization. WHO Laboratory Manual for the Examination and Processing of Human Semen. 5th ed. Geneva: World Health Organization (2010) p. 271.

40. Johansson LH, Borg LAH. A spectrophotometric method for determination of catalase activity in small tissue samples. Anal Biochem. (1988) 174:331-6. doi: 10.1016/0003-2697(88)90554-4

41. Wheeler CR, Salzman JA, Elsayed NM, Omaye ST, Korte DW. Automated assays for superoxide-dismutase, catalase, glutathione-peroxidase, and glutathione-reductase activity. Anal Biochem. (1990) 184:193-9. doi: 10.1016/0003-2697(90)90668-Y 
42. Ohkawa H, Ohishi N, Yagi K. Assay for lipid peroxides in animal tissues by thiobarbituric acid reaction. Anal Biochem. (1979) 95:351-8. doi: 10.1016/0003-2697(79)90738-3

43. Yagi K. Simple assay for the level of total lipid peroxides in serum or plasma. Methods Mol. Biol. (1998) 108:101-6. doi: 10.1385/0-89603-472-0:101

44. World Health Organization. Fruit and Vegetables for Health: Report of the Joint FAO/WHO Workshop on Fruit and Vegetables for Health. Kobe (2005).

45. Mendiola J, Torres-Cantero AM, Vioque J, Moreno-Grau JM, Ten J, Roca $\mathrm{M}$, et al. low intake of antioxidant nutrients is associated with poor semen quality in patients attending fertility clinics. Fertil Steril. (2010) 93:1128-33. doi: 10.1016/j.fertnstert.2008.10.075

46. Akmal M, Qadri JQ, Al-Waili NS, Thangal S, Haq A, Saloom KY. Improvement in human semen quality after oral supplementation of vitamin C. J Med Food. (2006) 9:440-2. doi: 10.1089/jmf.2006.9.440

47. Tsuji H, Ohmura K, Nakashima R, Hashimoto M, Imura Y, Yukawa N, et al. Efficacy and safety of grapefruit juice intake accompanying tacrolimus treatment in connective tissue disease patients. Internal Med. (2016) 55:154752. doi: 10.2169/internalmedicine.55.5553

48. Haghighian HK, Haidari F, Mohammadi-Asl J, Dadfar M. Randomized, tripleblind, placebo-controlled clinical trial examining the effects of alpha-lipoic acid supplement on the spermatogram and seminal oxidative stress in infertile men. Fertil Steril. (2015) 104:318-24. doi: 10.1016/j.fertnstert.2015.05.014

49. Raigani M, Yaghmaei B, Amirjannti N, Lakpour N, Akhondi MM, Zeraati $\mathrm{H}$, et al. The micronutrient supplements, zinc sulphate and folic acid, did not ameliorate sperm functional parameters in oligoasthenoteratozoospermic men. Andrologia. (2014) 46:956-62. doi: 10.1111/and.12180

50. Schmid TE, Eskenazi B, Marchetti F, Young S, Weldon RH, Baumgartner A, et al. Micronutrients intake is associated with improved sperm DNA quality in older men. Fertil Steril. (2012) 98:1130-7. doi: 10.1016/j.fertnstert.2012.07.1126

51. Madej D, Pietruszka B, Kaluza J. The effect of iron and/or zinc diet supplementation and termination of this practice on the antioxidant status of the reproductive tissues and sperm viability in rats. J Trace Elem Med Biol. (2021) 64:126689. doi: 10.1016/j.jtemb.2020.126689

52. Kaluza J, Madej D, Rusaczonek A, Siedlecka E, Pietruszka B. The effect of iron and zinc supplementation and its discontinuation on liver antioxidant status in rats fed deficient diets. Eur J Nutr. (2014) 53:1083-92. doi: 10.1007/s00394-013-0610-y

53. Eroglu M, Sahin S, Durukan B, Ozakpinar OB, Erdinc N, Turkgeldi L, et al. Blood serum and seminal plasma selenium, total antioxidant capacity and coenzyme q10 levels in relation to semen parameters in men with idiopathic infertility. Biol Trace Elem Res. (2014) 159:46-51. doi: 10.1007/s12011-014-9978-7

54. Khosronezhad N, Colagar AH, Jorsarayi SG. T26248G-transversion mutation in exon7 of the putative methyltransferase Nsun7 gene causes a change in protein folding associated with reduced sperm motility in asthenospermic men. Reprod Fertil Dev. (2015) 27:471-80. doi: 10.1071/RD13371

55. Marzec-Wroblewska U, Kaminski P, Lakota P, Szymanski M, Wasilow K, Ludwikowski G, et al. Zinc and iron concentration and SOD activity in human semen and seminal plasma. Biol Trace Elem Res. (2011) 143:167-77. doi: 10.1007/s12011-010-8868-x

56. Roychoudhury S, Sharma R, Sikka S, Agarwal A. Diagnostic application of total antioxidant capacity in seminal plasma to assess oxidative stress in male factor infertility. J Assist Reprod Gen. (2016) 33:627-35. doi: 10.1007/s10815-016-0677-5

57. Mahfouz R, Sharma R, Sharma D, Sabanegh E, Agarwal A. Diagnostic value of the total antioxidant capacity (TAC) in human seminal plasma. Fertil Steril. (2009) 91:805-11. doi: 10.1016/j.fertnstert.2008.01.022

58. Gupta S, Finelli R, Agarwal A, Henkel R. Total antioxidant capacityrelevance, methods and clinical implications. Andrologia. (2021) 53:e13624. doi: 10.1111 /and.13624

59. Belkaid Y, Hand TW. Role of the microbiota in immunity and inflammation. Cell. (2014) 157:121-41. doi: 10.1016/j.cell.2014.03.011
60. Ma YS, Hebert JR, Li WJ, Bertone-Johnson ER, Olendzki B, Pagoto SL, et al. Association between dietary fiber and markers of systemic inflammation in the Women's Health Initiative Observational Study. Nutrition. (2008) 24:941-9. doi: 10.1016/j.nut.2008.04.005

61. Gaskins AJ, Colaci DS, Mendiola J, Swan SH, Chavarro JE. Dietary patterns and semen quality in young men. Hum Reprod. (2012) 27:2899-907. doi: 10.1093/humrep/des298

62. Chiu YH, Gaskins AJ, Williams PL, Mendiola J, Jorgensen N, Levine H, et al. Intake of fruits and vegetables with low-to-moderate pesticide residues is positively associated with semen-quality parameters among young healthy men. J Nutr. (2016) 146:1084-92. doi: 10.3945/jn.115.226563

63. Abdollahi M, Ranjbar A, Shadnia S, Nikfar S, Rezaie A. Pesticides and oxidative stress: a review. Med Sci Monit. (2004) 10:141-7.

64. Balachandar R, Bagepally BS, Kalahasthi R, Haridoss M. Blood lead levels and male reproductive hormones: a systematic review and meta-analysis. Toxicology. (2020) 443:152574. doi: 10.1016/j.tox.2020.152574

65. Colla G, Kim HJ, Kyriacou MC, Rouphael Y. Nitrate in fruits and vegetables. Sci Hortic-Amsterdam. (2018) 237:221-38. doi: 10.1016/j.scienta.2018. 04.016

66. EFSA. Overview on Tolerable Upper Intake Levels as derived by the Scientific Committee on Food (SCF) and the EFSA Panel on Dietetic Products, Nutrition and Allergies (NDA) Summary of Tolerable Upper Intake Levels Online Material version 4 (2018).

67. Chen Q, Yang H, Zhou N, Sun L, Bao H, Tan L, et al. Inverse Ushaped association between sleep duration and semen quality: longitudinal observational study (MARHCS) in Chongqing, China. Sleep. (2016) 39:79-86. doi: $10.5665 /$ sleep. 5322

68. Minguez-Alarcon L, Chavarro JE, Mendiola J, Gaskins AJ, Torres-Cantero AM. Physical activity is not related to semen quality in young healthy men. Fertil Steril. (2014) 102:1103-9. doi: 10.1016/j.fertnstert.2014.06.032

69. Gaskins AJ, Afeiche MC, Hauser R, Williams PL, Gillman MW, Tanrikut C, et al. Paternal physical and sedentary activities in relation to semen quality and reproductive outcomes among couples from a fertility center. Hum Reprod. (2014) 29:2575-82. doi: 10.1093/humrep/deu212

70. Vaamonde D, Da Silva-Grigoletto ME, Garcia-Manso JM, Barrera N, Vaamonde-Lemos R. Physically active men show better semen parameters and hormone values than sedentary men. Eur J Appl Physiol. (2012) 112:3267-73. doi: 10.1007/s00421-011-2304-6

71. Gill K, Jakubik J, Kups M, Rosiak-Gill A, Kurzawa R, Kurpisz M, et al. The impact of sedentary work on sperm nuclear DNA integrity. Folia Histochem Cytobiol. (2019) 57:15-22. doi: 10.5603/FHC.a2019.0002

72. Stokes-Riner A, Thurston SW, Brazil C, Guzick D, Liu F, Overstreet JW, et al. One semen sample or 2? Insights from a study of fertile men J Androl. (2007) 28:638-43. doi: 10.2164/jandrol.107.002741

Conflict of Interest: The authors declare that the research was conducted in the absence of any commercial or financial relationships that could be construed as a potential conflict of interest.

Publisher's Note: All claims expressed in this article are solely those of the authors and do not necessarily represent those of their affiliated organizations, or those of the publisher, the editors and the reviewers. Any product that may be evaluated in this article, or claim that may be made by its manufacturer, is not guaranteed or endorsed by the publisher.

Copyright (c) 2021 Madej, Granda, Sicinska and Kaluza. This is an open-access article distributed under the terms of the Creative Commons Attribution License (CC $B Y)$. The use, distribution or reproduction in other forums is permitted, provided the original author(s) and the copyright owner(s) are credited and that the original publication in this journal is cited, in accordance with accepted academic practice. No use, distribution or reproduction is permitted which does not comply with these terms. 